\title{
The Role of Complement in the Opsonization of Mucoid and Non-Mucoid Strains of Pseudomonas Aeruginosa
}

\author{
ROBERT S. BALTIMORE ${ }^{(18)}$ AND DUANE G. SHEDD \\ Departments of Pediatrics and of Epidemiology and Public Health, Yale Universty School of Medicine, \\ New Haven, Connecticut, USA
}

\begin{abstract}
Summary
Requirements for complement and/or antibody for opsonization were assessed for 34 strains of Pseudomonas aeruginosa. Included were mucoid strains from patients with cystic fibrosis (CF), non-mucoid derivatives of these strains, and non-CF strains with classical morphology. Non-CF strains are known to vary as to opsonic requirements, but this study shows that mucoid strains are also diverse. Among the 14 mucoid strains, five could not be opsonized and completely resisted phagocytosis. All non-mucoid strains can be opsonized. When the bacteria were incubated in fresh human serum and stained with fluorescein, conjugated anti$\mathrm{C} 3$ non-opsonizable strains did not bind $\mathrm{C} 3$ on the surface whereas five of six mucoid strains, which could be opsonized by complement alone, stained with anti-C3. In mucoid strains, surface characteristics correlate with differences in functional requirements for opsonization. In non-CF strains this specificity was not seen. Most mucoid strains required an intact classical complement pathway for opsonization. A number of mucoid strains could not be opsonized in the absence of a functional alternative complement pathway whereas in contrast, non-CF strains were not greatly affected by inactivation of the alternative pathway.
\end{abstract}

Abbreviations

AS, rabbit antiserum

$\mathrm{C}$, complement

CF, cystic fibrosis

cfu, colony forming units

CPA, classical (non-mucoid) $P$. aeruginosa

HBSS, Hank's balanced salt solution

MEM, Eagle's minimum essential medium with Earle's balanced salt solution

MPA, mucoid $P$. aeruginosa

NMPA, non-mucoid $P$. aeruginosa derivatives

PMN, polymorphonuclear leukocyte

Colonization of the upper and middle airway with Pseudomonas aeruginosa is commonly encountered in patients with $\mathrm{CF}$. In patients with $\mathrm{CF}$ who have advanced respiratory disease, isolates of $P$. aeruginosa frequently have a mucoid colonial morphology when grown on solid media $(11,14)$. These isolates of MPA are not eradicated from the respiratory tracts of patients with $C F$ by antibiotic therapy, and they persist in the presence of serum antibody to $P$. aeruginosa $(6,8)$. It was recently demonstrated in our laboratory that certain strains of MPA are resistant to opsonization, compared with non-mucoid strains derived from these mucoid strains (2). These studies employed rabbit antisera specific for the seven immunotypes according to the procedure of Fisher et al. (7). Eight MPA strains were used for comparison with their NMPA selected from 30 original strains by two criteria: (1) they were typable by agglutination according to the immunotype scheme of Fisher et al. and (2) they could not be killed in vitro unless antiserum and PMN were present. Strains were thus excluded if there was ingestion and killing of $\geq 90 \%$ of the initial inoculum by PMN; or by PMN and $C$ together; or, if they were killed, by $C$ plus AS without PMN. In that study the conclusion was that MPA strains which were not killed in the presence of PMN and C, were then relatively resistant to antibody opsonization compared with NMPA strains derived from the same strains. It was hypothesized that this was due to interference of antibody attachment by the mucoid material. Strains opsonized by $\mathrm{C}$ alone were not further studied in detail in that study. In the study alluded to, preliminary studies of complement activation were reported. By inhibition assays, two MPA strains appeared to activate alternative complement pathway. We now report the details of opsonic requirements of these MPA strains, especially their complement binding, and compare them with their NMPA derivatives and conventional, CPA isolated from patients who did not have CF.

\section{MATERIALS AND METHODS}

Pseudomonas aeruginosa strains. MPA were isolated from sputum cultures of children seen at the Cystic Fibrosis Center at the Yale-New Haven Hospital, New Haven, CT, and were identified as such in the Clinical Microbiology Laboratory. Nonmucoid derivatives of these strains were obtained by repeatedly subculturing the mucoid strains on Mueller-Hinton agar and isolating morphologically recognizable non-mucoid colonies. $P$. aeruginosa isolates from non-CF patients were obtained from hospitalized pediatric and adult patients with infections due to these isolates and had classical morphology. These were isolates from a previous study at Walter Reed Army Medical Center and are designated CPA strains (1). All strains were lyophilized in skim milk. They have been shown by serial photographs to retain morphologic colonial characteristics for several years by this method (unpublished studies). The strains used in this study were all typed by agglutination with rabbit antisera according to the scheme of Fisher et al. (7); however, the MPA strains could not be accurately typed by this method until they changed to NMPA as previously reported (2).

Rabbit antisera to immunotype strains. Rabbit antisera were obtained by IV immunization of young adult rabbits with whole, live organisms of each of the seven immunotype strains according to the schedule previously published (1). These strains were obtained from Parke, Davis and Co., Detroit, MI.

Opsonophagocytic assay. The method of Baltimore and Mitch- 
ell (2) was used to measure opsonization. Plate-grown organisms were inoculated into shaking cultures in Mueller Hinton broth and incubated until they reached an optical density that corresponds to $4 \times 10^{8} \mathrm{cfu} / \mathrm{ml}$, at which time they were in the logphase of growth. Ten milliliters of the culture were removed, centrifuged at $12,000 \times g$ for $10 \mathrm{~min}$, and resuspended in $10 \mathrm{ml}$ of MEM (Microbiological Associates, Bethesda, MD). In the studies of complement inhibition, Hank's balanced salt solution without calcium or magnesium (Gibco Laboratories, Grand Island, NY) was used as a diluent.

In $12 \times 75 \mathrm{~mm}$ polypropylene tubes (Falcon Plastics, Los Angeles, CA), $0.5 \mathrm{ml}$ were added of a mixture containing $0.3 \mathrm{ml}$ of the PMN suspension $\left(\sim 10^{7}\right.$ PMN $)$, obtained by dextran sedimentation of heparinized whole human blood from a normal adult volunteer, $0.05 \mathrm{ml}$ of antiserum, $0.05 \mathrm{ml}$ of complement, $0.05 \mathrm{ml}$ of the bacterial suspension containing $2 \times 10^{7} \mathrm{cfu}$, and $0.05 \mathrm{ml}$ of MEM. In addition, four control tubes were included in each test: one in which antiserum was omitted, one in which complement was omitted, one in which PMN was omitted, and one in which both antiserum and complement were omitted. In these tubes MEM replaced the omitted component. The tubes were incubated at $37^{\circ} \mathrm{C}$ for $60 \mathrm{~min}$ with end-over-end rotation by a Fisher Roto-Rack (Fisher Scientific, Pittsburgh, PA).

At the beginning of the incubation of the opsonic test and after $60 \mathrm{~min}$ of incubation, samples $(0.05 \mathrm{ml})$ were removed from the tubes. These aliquots were diluted 1:100 in distilled water, which produced lysis of PMN and release of bacteria, and dilution colony counts were made on Mueller-Hinton agar plates. Total colony counts representing intra- and extracellular bacteria were performed after incubation overnight. Results were expressed as $\log _{10} \mathrm{cfu}$ reduction according to the formula $\log _{10}$ (cfu at $0 \mathrm{~min} / \mathrm{cfu}$ at $60 \mathrm{~min}$ ). A $\log _{10} \mathrm{cfu}$ reduction of $\geq 1.0$ (equivalent to $\geq 90 \%$ killing of bacteria in $60 \mathrm{~min}$ ) was considered to be evidence of significant opsonization. Pseudomonas aeruginosa ingested by PMN are quickly killed so cfu reduction is an accurate estimate of opsonization $(2,15)$. A positive control run simultaneously in which PMN, C, and AS were present must have $\geq 1.0 \log _{10}$ cfu reduction for the test to be considered valid. In cases where the test strain was not opsonized by $\mathrm{C}$ plus $\mathrm{AS}$ the control was another strain and homologous antiserum tested with the same PMN and C.

Complement. The source of complement was fresh serum from a normal adult volunteer. The serum was absorbed with whole live organisms of the strain to be tested by the method of Kasper and Wyle (10). The serum was absorbed at $4^{\circ} \mathrm{C}$ for $1 \mathrm{~h}$, centrifuged at $12,000 \times g$ for $2 \mathrm{~min}$, reabsorbed at $4^{\circ} \mathrm{C}$ for $1 \mathrm{~h}$, centrifuged in a cold room and then filter-sterilized. Complement-dependent opsonophagocytic assays were included as a positive control to demonstrate that activity remains after absorption.

Inhibition of the alternative complement pathway was accomplished by absorption with zymosan (4). Zymosan $(50 \mathrm{mg} / \mathrm{ml})$ was suspended in veronal buffered saline, $\mathrm{pH}$ 7.4. This suspension was boiled for $1 \mathrm{~h}$ then washed twice with saline. The fresh human serum absorbed with the test strain was then absorbed twice with $2 \mathrm{mg}$ of zymosan per $1.0 \mathrm{ml}$ of serum $(0.04 \mathrm{ml}$ of the above suspension) by incubating the serum for $60 \mathrm{~min}$ at $15-$ $17^{\circ} \mathrm{C}$ with constant shaking. With each absorption $0.02 \mathrm{ml}$ of 1 $\mathrm{M} \mathrm{MgCl}$ is added. After each absorption the mixture is centrifuged for $30 \mathrm{~min}$ at $12,000 \times g$ at $4^{\circ} \mathrm{C}$. The supernatant is removed and stored on ice until used.

Inhibition of the classical complement pathway was accomplished by the addition of $0.01 \mathrm{M}$ EGTA by the method described by Johnston et al. (9).

Fluorescent staining methods. Strains of $P$. aeruginosa were grown in log-phase as for the opsonophagocytic assays. A mixture containing $2 \times 10^{7} \mathrm{cfu}$ of bacteria, and $10 \%$ complement in a total volume of $0.5 \mathrm{ml}$ was placed into a $12 \times 75 \mathrm{~mm}$ polypropylene tube. This mixture was incubated at $37^{\circ} \mathrm{C}$ for $30 \mathrm{~min}$ with end-over-end rotation. For experiments in which the effect of antibody-containing serum was tested, the tubes contained $2 \times$ $10^{7} \mathrm{cfu}, 10 \%$ complement, and $10 \%$ rabbit antiserum to the homologous immunotype strain.

At the end of the 30 -min incubation, the mixture was centrifuged for $2 \mathrm{~min}$ at $12,000 \times g$ and resuspended in $0.5 \mathrm{ml}$ of MEM. A drop of the suspension was placed on each slide to be stained and then air-dried. These slides were stained with either fluorescein isothiocyanate-conjugated sheep antiserum to rabbit immunoglobulin (Wellcome Reagents, Triangle Park, NC), goat antiserum to human C4 (Atlantic Antibodies, Westbrook, ME), or goat antiserum to human C3 (Hyland, Travenol Laboratories, Costa Mesa, CA). Each was diluted to a ratio of $1: 40$. The slides were stained for $20 \mathrm{~min}$ in a moist chamber at $37^{\circ} \mathrm{C}$ and washed three times with phosphate buffered saline. The slides were scanned at $\times 1000$ using a fluorescence microscope and fluorescence was recorded. These observations were made with the slides coded and the observer blind to which organisms and which antiserum were on the slide.

Statistical analysis. Significant difference of binding complement on the surface of bacterial stains with different opsonic requirements was determined by the use of the Fisher exact test (two-tailed).

\section{RESULTS}

Immunofluorescencec Outlines of the bacteria could be seen easily when stained with anti-C3 (Fig. 1) or anti-C4 (Fig. 2), but they were not as bright as bacteria stained with anti-rabbit immunoglobulin (Fig. 3). There was no non-specific binding of fluorescent antisera. For these negative controls, each $P$. aeruginosa strain was incubated with saline and no complement or antiserum. No bacteria were visible and the backgrounds were dark; therefore, we scored fluorescence as either positive or negative although there was a considerable difference in qualitative brightness of the fluorescence.

In these studies a total of 34 strains, all typable, were tested for binding of $\mathrm{C} 3$ and $\mathrm{C} 4$. There were 14 MPA strains, 11 NMPA strains and 9 CPA strains.

Immunofluorescence with anti-C3 and anti-C4. All of the strains were tested for binding of $\mathrm{C} 3$ and $\mathrm{C} 4$ in the presence of $\mathrm{C}$ and $\mathrm{C}$ plus AS. Of the 14 MPA strains, five (35.7\%) bound C3; four of 11 NMPA (36.4\%) bound C3; and none of the CPA bound $\mathrm{C} 3$ in the presence of $\mathrm{C}$ without AS. Three of the $14 \mathrm{MPA}$ (21.4\%) bound C4, one of the $11(9.1 \%)$ NMPA, and none of the nine CPA in the presence of $\mathrm{C}$ alone. All strains that bound C4 (MPA and NMPA) also bound C3 (Table 1).

Correlation of opsonophagocytosis with immunofluorescence. The opsonic requirements of each strain were determined by noting the $\log _{10}$ reduction of cfu in the presence of PMN, $C$ and $\mathrm{AS}$ and in the control tests with PMN and C, PMN plus AS, and $\mathrm{C}$ and AS. The AS in each case was rabbit antiserum to the prototype strain of the same immunotype as the test strain. Each of these combinations was scored as opsonophagocytic if there were $\geq 1.0 \log _{10}$ cfu reduction in $60 \mathrm{~min}$. Each strain was classified as to the minimum constituents required for opsonization. The strains of each classification were then divided as to whether they bound $\mathrm{C} 3$ and/or $\mathrm{C} 4$ in the immunofluorescence test.

Table 1 summarizes the results of opsonization and immunofluorescence for all of the 34 strains tested. They are classified by morphology and origin into MPA, NMPA, and CPA and then by opsonic requirements. For each strain it is indicated whether $\mathrm{C} 3$ and $\mathrm{C} 4$ were bound either in the presence or absence of $10 \%$ rabbit antisera to the homologous immunotype strain. Table 2 summarizes the diversity of opsonic requirements of strains of each morphology or origin. Table 3 shows the correlations of opsonic requirements and $\mathrm{C} 3$ binding. It can be seen that of the 14 MPA strains, only those which could be opsonized by $\mathrm{C}$ bound $\mathrm{C} 3$ when incubated with fresh absorbed human serum. Of these six strains, five of them bound $\mathrm{C} 3$ on the surface. The significance of the association of $\mathrm{C} 3$ binding and opsoniza- 


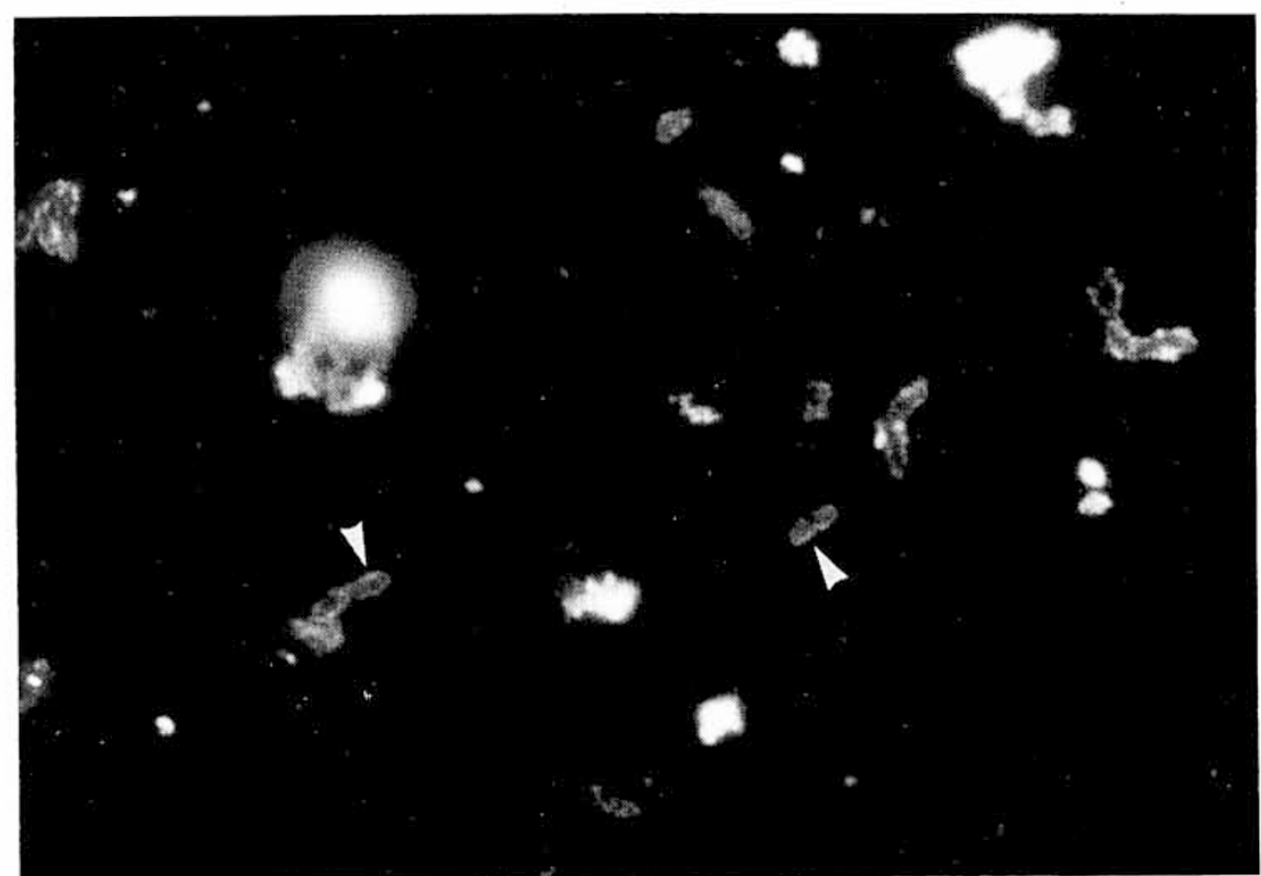

Fig. 1. Immunofluorescence of Pseudomonas aeruginosa incubated with fresh normal human serum and stained with fluorescein isothiocyanate conjugated goat antiserum to $\mathrm{C} 3(\times 1000)$. Arrows point to stained bacteria.

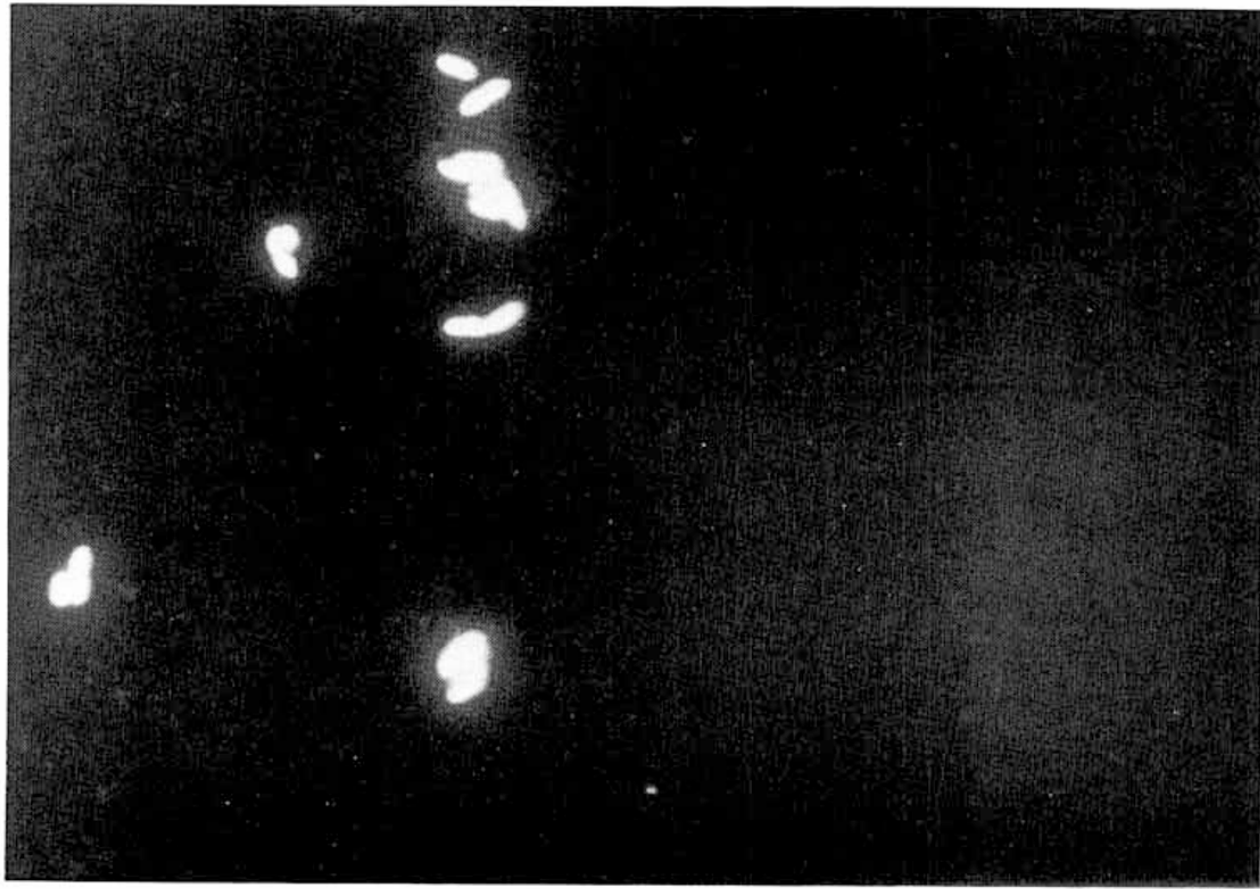

Fig. 2. Immunofluorescence of Pseudomonas aeruginosa incubated with fresh normal human serum and stained with fluorescein isothiocyanate conjugated goat antiserum to $C 4(\times 1000)$. Arrow points to a clump of stained bacteria.

tion of MPA strains by $\mathrm{C}$ alone was tested by comparing $\mathrm{C} 3$ binding in MPA strains with different opsonic requirements. There was a significant difference in $\mathrm{C} 3$ binding between MPA strains opsonized by $\mathrm{C}$ alone and MPA strains not opsonizable $(P=0.015)$ as well as between strains opsonized by $C$ alone and all MPA strains not opsonized by $\mathrm{C}$ alone $(P=0.003)$. There were no significant associations with $\mathrm{C} 3$ binding and opsonic requirements for NMPA nor CPA strains. Table 4 shows similar correlations for binding of $\mathrm{C} 4$. It can be seen in this table that only MPA strains that could be opsonized by $\mathrm{C}$ could bind $\mathrm{C} 4$, but only three of the six strains of this classification were positive for $\mathrm{C} 4$ binding. These three strains were three of the five MPA strains which bound C3. Of the 11 NMPA strains, four of them bound $\mathrm{C} 3$ but these were from all three groups based on opsonic requirements. None of the CPA strains bound $\mathrm{C} 3$ or $\mathrm{C} 4$ when incubated in $\mathrm{C}$. There were no significant correlations between opsonic requirements and binding of $\mathrm{C} 4$.

These strains were also tested for immunofluorescence in the presence of $10 \%$ complement and $10 \%$ rabbit antiserum. These results are shown in Table 1 . In these tests 11 of the 14 MPA strains bound C3. Two of the MPA strains, which did bind C3, were two of the five strains which could not be opsonized. Of the 11 NMPA strains, eight bound $\mathrm{C} 3$ in the presence of complement and antiserum. Those that did not bind C3 included 


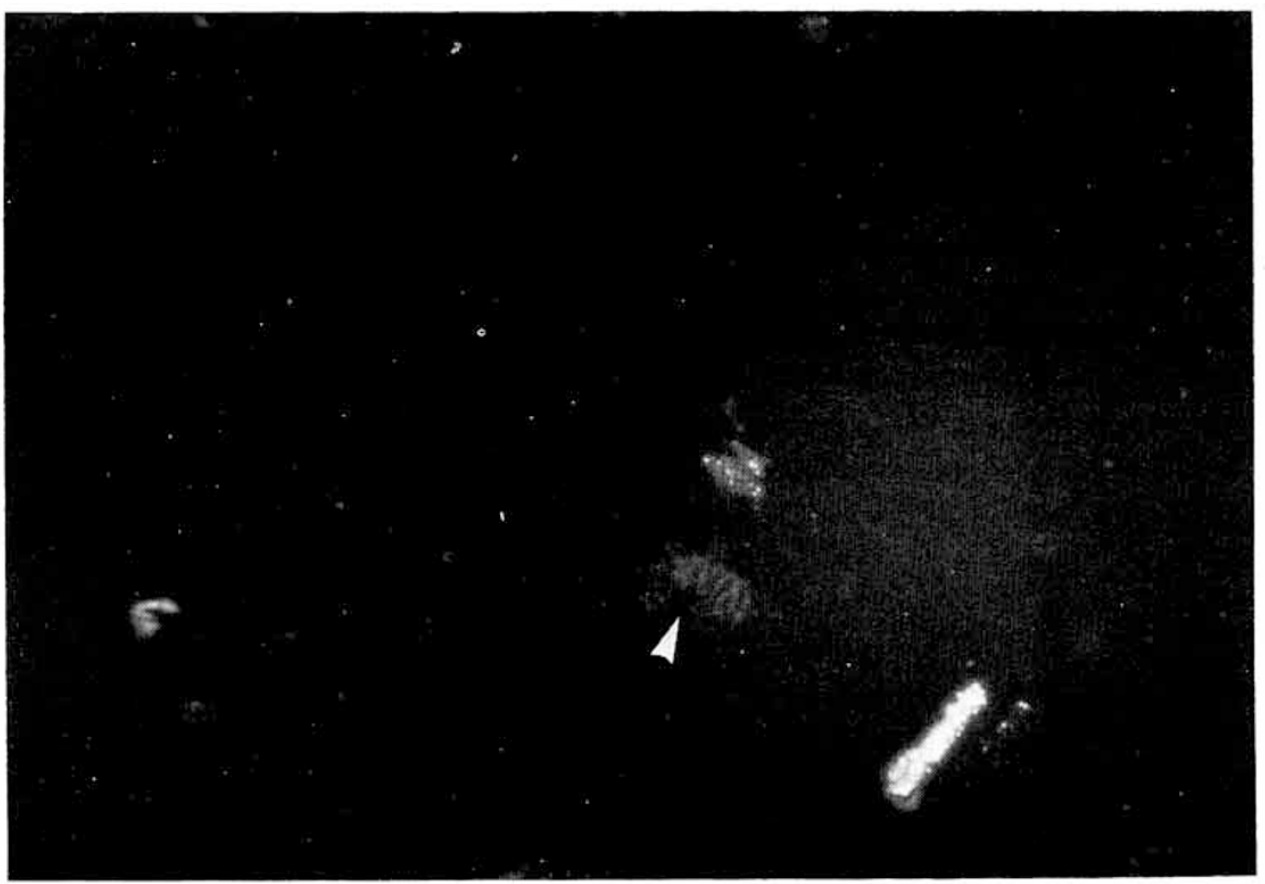

Fig. 3. Immunofluorescence of Pseudomonas aeruginosa incubated with complement and immune rabbit serum and stained with fluorescein isothiocyanate conjugated sheep antiserum to rabbit immunoglobulin $(\times 1000)$.

one strain which could be opsonized by $\mathrm{C}(218 \mathrm{NM})$ and two which required antiserum for opsonization. Of the 11 NMPA, six bound $\mathrm{C} 4$ in the presence of complement and antiserum and all of these were strains that bound $\mathrm{C} 3$. Of the nine CPA strains, seven bound $\mathrm{C} 3$ in the presence of complement and antiserum and five of these bound $\mathrm{C} 4$. The two strains which did not bind C3 were the two strains requiring $\mathrm{AS}$ and $\mathrm{C}$ for opsonization. None of the CPA strains could be killed by bacteriolysis in the absence of PMN.

Complement inhibition. We investigated the complement pathways involved in opsonization of the $P$. aeruginosa strains to determine if binding of $\mathrm{C} 3$ and $\mathrm{C} 4$ was reflected in utilization of the classical or alternative complement pathways. In these tests all strains were opsonized by the minimum opsonic requirements that we had determined from previous experiments. These are shown in the column "opsonic requirement" in Table 5. Complement was present in all tests, but only for those strains which required rabbit antibody for $\geq 1.0 \log _{10}$ kill was antiserum of that immunotype added. All strains were tested by inhibiting the alternative complement pathway by incubation of complement with zymosan or inhibition of the classical complement pathway by adding the chelator, EGTA. For analysis, the $\log _{10}$ reduction of $\mathrm{cfu}$ in the presence of each inhibitor was compared to the results without inhibitor. For EGTA inhibition studies the diluent was HBSS without magnesium or calcium and the control without inhibitor was performed with the same diluent. We have found that the effect of EGTA can be seen best in this medium. In standard HBSS, chelation with EGTA is often without effect on opsonization whereas in the special HBSS there is a remarkable effect of chelation. This is a change in methods from our previous report. Differences in results from previous studies are attributable to this change in procedure (2). For zymosan inhibition studies, HBSS with calcium and magnesium was used. The results of the studies of several of the representative strains are shown in Table 5. Both zymosan and EGTA were potent inhibitors of opsonization of most of the strains.

The immunofluorescent studies demonstrated that among MPA strains, divisions could be correlated with opsonic requirements. Table 5 shows the results of opsonophagocytosis of two representative MPA strains which were able to be opsonized by complement. Chelation with EGTA inhibited the killing of all of these strains and in its presence opsonization of the six MPA and five NMPA strains tested resulted in considerably less than $1.0 \log _{10}$ reduction of cfu. The two strains shown in Table 5 were also opsonized with normal and C4-deficient guinea pig serum. In opsonophagocytic tests of strains $106 \mathrm{M}$ and $127 \mathrm{M}$, the effect of C4-deficient guinea pig serum was similar to that shown for EGTA chelation of human serum. Strain $106 \mathrm{M}$ had a $\log _{10}$ reduction of cfu of 1.23 in normal guinea pig serum and 0.27 in C4-deficient guinea pig serum. For strain $127 \mathrm{M}$ the results were 1.33 and 0.82 , respectively. Not all MPA strains were opsonized poorly by $\mathrm{C} 4$ deficient serum.

The degree of inhibition by zymosan was more variable than that with EGTA and, like EGTA inhibition, it was not related to morphology or opsonic requirements. For MPA strains opsonized by complement the inhibition by zymosan was less than EGTA suggesting less opsonic activity was due to the alternative complement pathway, but the variability indicated by the two strains shown in Table 5 indicates this is a strain-specific phenomenon. There was variation within this group as demonstrated by opsonization of strain $106 \mathrm{M}$, which was only slightly inhibited, and $127 \mathrm{M}$ in which activity was considerably inhibited by zymosan. Among the six MPA strains opsonized by complement, for three strains opsonic activity of complement was reduced to $<0.2 \log _{10}$ reduction in cfu by zymosan $(108 \mathrm{M}, 119 \mathrm{M}$, and $153 \mathrm{M})$ and for two strains (115M and $106 \mathrm{M})$ there was some inhibition of killing but significant activity remained (approximately $1.0 \log _{10}$ reduction of $\mathrm{cfu}$ ) with zymosan. NMPA strains showed a similar diversity. In Table 5 it can be seen that opsonization of 207 NMPA was similar to the two MPA strains which could be opsonized by $\mathrm{C}$, but $113 \mathrm{NM}$ could not be opsonized in $\mathrm{C}$ treated with zymosan.

Opsonization of the CPA strains was less affected by zymosan inhibition than the other strains were. The results for two strains are shown in Table 5. These two as well as the seven other CPA strains were opsonized by zymosan-treated complement. Opsonization of most CPA strains was more inhibited by EGTAchelated complement than by zymosan treatment, but some strains such as 565 , which was opsonized by heat-inactivated antiserum alone, were affected very little by complement inactivators. The CPA strains appear to require an intact classical complement pathway for optimal amplification of opsonic anti- 
Table 1. Opsonic requirements and complement component binding of 34 mucoid and non-mucoid strains of Pseudomonas aeruginosa ${ }^{1}$

\begin{tabular}{|c|c|c|c|c|c|c|}
\hline \multirow[b]{2}{*}{$\begin{array}{c}\text { Strain } \\
\text { number }\end{array}$} & \multirow[b]{2}{*}{ Classification } & \multirow[b]{2}{*}{$\begin{array}{c}\text { Opsonic } \\
\text { requirement }\end{array}$} & \multicolumn{2}{|c|}{ Incubated in $\mathrm{C}$} & \multicolumn{2}{|c|}{ Incubated in $C+A S$} \\
\hline & & & $\begin{array}{l}\text { Anti } \\
\text { C3 }\end{array}$ & $\begin{array}{c}\text { Anti } \\
\text { C4 }\end{array}$ & $\begin{array}{l}\text { Anti } \\
\text { C3 }\end{array}$ & $\begin{array}{c}\text { Anti } \\
\text { C4 }\end{array}$ \\
\hline 108 & MPA & $\mathrm{C}$ & + & - & + & - \\
\hline 115 & MPA & $\mathrm{C}$ & + & - & + & + \\
\hline 127 & MPA & $\mathrm{C}$ & + & + & + & + \\
\hline 225 & MPA & $\mathrm{C}$ & + & + & + & + \\
\hline 116 & MPA & $\mathrm{C}+\mathrm{AS}$ & - & - & + & - \\
\hline 119 & MPA & $C+A S$ & - & - & + & + \\
\hline 109 & MPA & $\mathrm{R}$ & - & - & - & - \\
\hline 112 & MPA & $\mathrm{R}$ & - & - & - & - \\
\hline 113 & MPA & $\mathrm{R}$ & - & - & + & - \\
\hline 131 & MPA & $\mathrm{R}$ & - & - & - & - \\
\hline 207 & NMPA & $\mathrm{C}$ & - & - & + & + \\
\hline 218 & NMPA & $\mathrm{C}$ & - & - & - & - \\
\hline 112 & NMPA & AS & + & - & - & - \\
\hline 119 & NMPA & AS & + & - & + & + \\
\hline 132 & NMPA & AS & - & - & - & - \\
\hline 101 & NMPA & $\mathrm{C}+\mathrm{AS}$ & + & - & + & - \\
\hline 113 & NMPA & $\mathrm{C}+\mathrm{AS}$ & - & - & + & + \\
\hline 124 & NMPA & $C+A S$ & - & - & + & + \\
\hline 575 & $\mathrm{CPA}$ & $\mathrm{C}$ & - & - & + & + \\
\hline 885 & $\mathrm{CPA}$ & $\mathrm{C}$ & - & - & + & - \\
\hline 407 & $\mathrm{CPA}$ & AS & - & - & + & - \\
\hline 565 & $\mathrm{CPA}$ & AS & - & - & + & + \\
\hline
\end{tabular}

${ }^{1}$ Abbreviations and explanations: MPA, mucoid $P$. aeruginosa; NMPA, nonmucoid derivative of an MPA strain; CPA, classical $P$. aeruginosa strain; C, complement; AS, rabbit antiserum; $\mathrm{R}$, resistant to opsonophagocytosis with $\mathrm{C}+\mathrm{AS} ;+$, visible staining of bacteria with fluorescent antiserum; and -, no visible staining of bacteria with fluorescent antiserum.

Table 2. Opsonic requirements of Pseudomonas aeruginosa strains $^{1}$

\begin{tabular}{cccccc}
\hline \multirow{2}{*}{$\begin{array}{c}\text { Strain } \\
\text { classification }\end{array}$} & C & AS & C + AS & R & Total \\
\cline { 2 - 6 } & 6 & 1 & 2 & 5 & 14 \\
MPA & 5 & 3 & 3 & 0 & 11 \\
NMPA & 2 & 5 & 2 & 0 & 9 \\
CPA & 2 & 5 &
\end{tabular}

${ }^{1}$ Abbreviations: $\mathrm{C}$, complement; $\mathrm{AS}$, rabbit antiserum to homologous immunotype; and $\mathrm{R}$, resistant to opsonization by $\mathrm{C}+\mathrm{AS}$.

body activity but against certain strains there was still considerable activity when the classical pathway was inhibited.

\section{DISCUSSION}

The role of complement in the opsonization of Pseudomonas aeruginosa has been the subject of a number of previous investigations. These investigations have dealt primarily with CPA strains. Bjornson and Michael (3) showed that "heat labile" factors, presumably complement, were required along with antibody to opsonize $P$. aeruginosa for phagocytosis by mouse leukocytes. Young and Armstrong (15) showed that the heat labile factor was complement for one strain of $P$. aeruginosa, and by the use of complement inhibitors demonstrated a requirement for complement components $1-4$, for near-optimal opsonization and that EGTA was a potent inhibitor. Young (16) suggested that both the alternative and classical complement pathways lead to significant activation of $\mathrm{C} 3$. Bjornson and Michael (4) also demonstrated a role for properden and thus the alternative complement pathway for a CPA strain tested in the absence of antibody. In the presence of antibody this requirement was abolished.

Peterson et al. (12) studied the opsonization of six strains of $P$. aeruginosa, measuring the uptake radiolabeled $P$. aeruginosa into human PMN. Using fresh normal human serum as a source of complement they showed that complement was essential for opsonization. Five strains could be opsonized in the absence of intact classical pathway (using $\mathrm{C} 2$ and $\mathrm{C} 4$ deficient sera) but at a slower than optimal rate. They found that opsonization via the alternative complement pathway was strain-dependent. Of two strains reported on, opsonization of one was only $30 \%$ compared with normal serum but another was opsonized essentially the same in normal and zymosan-treated serum. They showed that the strain which was opsonized in zymosan-treated serum still bound $\mathrm{C} 3$ (demonstrated by immunofluorescence). This strain behaved like seven of the nine CPA strains we studied, whose opsonization was not inhibited by zymosan treatment of the opsonic source but bound C3 in the presence of antiserum to 
Table 3. Immunoflutorescence of 34 strains of Pseudomonas aeruginosa incubated with human complement and stained with anti$C 3^{1}$

\begin{tabular}{|c|c|c|c|c|c|c|}
\hline \multirow{2}{*}{$\begin{array}{c}\text { Strain } \\
\text { classification }\end{array}$} & \multirow{2}{*}{$\begin{array}{c}\text { Staining with } \\
\text { anti-C3 }\end{array}$} & \multicolumn{5}{|c|}{ Opsonic requirement (number of strains) } \\
\hline & & $\mathrm{C}$ & AS & $\mathrm{C}+\mathrm{AS}$ & $\mathrm{R}$ & Total \\
\hline \multirow[t]{2}{*}{ MPA } & Positive & $5^{*}$ & 0 & 0 & 0 & 5 \\
\hline & Negative & $1^{*}$ & 1 & 2 & 5 & 9 \\
\hline \multirow[t]{2}{*}{ NMPA } & Positive & 1 & 2 & 1 & 0 & 4 \\
\hline & Negative & 4 & 1 & 2 & 0 & 7 \\
\hline \multirow[t]{2}{*}{ CPA } & Positive & 0 & 0 & 0 & 0 & 0 \\
\hline & Negative & 2 & 5 & 2 & 0 & 9 \\
\hline
\end{tabular}

\footnotetext{
${ }^{1}$ Abbreviations: MPA, mucoid $P$. aeruginosa strains; NMPA, nonmucoid derivative of MPA strains; CPA, classical $P$. aeruginosa strains; $\mathrm{C}$, complement; AS, rabbit antiserum; and R, resistant to opsonization with C + AS. Asterisk $(*)$, staining with anti-C3 is significantly associated with an opsonic requirement for $\mathrm{C}$, compared with strains which were resistant to opsonization $(P=0.015)$ or compared with all strains not opsonized by $\mathrm{C}$ alone $(P=0.003)$.
}

Table 4. Immunofluorescence of 34 strains of Pseudomonas aeruginosa incubated with human complement and stained with anti$C 4^{1}$

\begin{tabular}{|c|c|c|c|c|c|c|}
\hline \multirow{2}{*}{$\begin{array}{c}\text { Strain } \\
\text { classification }\end{array}$} & \multirow{2}{*}{$\begin{array}{l}\text { Staining with } \\
\text { anti-C4 }\end{array}$} & \multicolumn{5}{|c|}{ Opsonic requirement (number of strains) } \\
\hline & & $\mathrm{C}$ & AS & $\mathrm{C}+\mathrm{AS}$ & $\mathrm{R}$ & Total \\
\hline \multirow[t]{2}{*}{ MPA } & Positive & 3 & 0 & 0 & 0 & 3 \\
\hline & Negative & 3 & 1 & 2 & 5 & 11 \\
\hline \multirow[t]{2}{*}{ NMPA } & Positive & 1 & 0 & 0 & 0 & 1 \\
\hline & Negative & 4 & 3 & 3 & 0 & 10 \\
\hline \multirow[t]{2}{*}{$\mathrm{CPA}$} & Positive & 0 & 0 & 0 & 0 & 0 \\
\hline & Negative & 2 & 5 & 2 & 0 & 9 \\
\hline
\end{tabular}

${ }^{1}$ Abbreviations: MPA, mucoid $P$, aeruginosa strains; NMPA, non-mucoid derivative of MPA strains; CPA, classical $P$. aeruginosa strains; C, complement; AS, rabbit antiserum; and $\mathrm{R}$, resistant to opsonization with $\mathrm{C}+\mathrm{AS}$.

Table 5. Effect of inhibitors of the classical and alternative complement pathway on opsonophagocytosis of selected strains of Pseudomonas aeruginosa ${ }^{1}$

\begin{tabular}{|c|c|c|c|c|c|c|}
\hline \multirow[b]{2}{*}{$\begin{array}{l}\text { Identification } \\
\text { number }\end{array}$} & \multirow[b]{2}{*}{ Classification } & \multirow[b]{2}{*}{$\begin{array}{l}\text { Opsonic } \\
\text { requirement }\end{array}$} & Control & Zymosan & Control & EGTA \\
\hline & & & \multicolumn{2}{|c|}{ (in HBSS) } & \multicolumn{2}{|c|}{ (in $\mathrm{HBSS}$, no $\mathrm{Ca}^{++}$or $\mathrm{Mg}^{++}$) } \\
\hline 106 & MPA & $\mathrm{C}$ & $1.54^{+}$ & 1.02 & 1.76 & 0.20 \\
\hline 127 & MPA & C & 1.23 & 0.38 & 2.00 & 0.55 \\
\hline 113 & NMPA & $C+A S$ & 1.65 & 0.27 & 2.15 & 0.01 \\
\hline 207 & NMPA & $\mathrm{C}$ & 1.88 & 1.04 & 2.68 & 0.00 \\
\hline 409 & $\mathrm{CPA}$ & $C+A S$ & 1.57 & 1.07 & 0.97 & 0.37 \\
\hline 565 & $\mathrm{CPA}$ & AS & 1.20 & 1.19 & 1.18 & 0.98 \\
\hline
\end{tabular}

${ }^{1}$ Abbreviations:,$+ \log _{10}$ reduction of colony forming units in $60 \mathrm{~min}$; MPA, mucoid $P$. aeruginosa; NMPA, non-mucoid derivative of an MPA strain; CPA, classical P. aeruginosa strain; C, complement; AS, rabbit antiserum; and HBSS, Hank's balanced salt solution.

the homologous immunotype. Another similarity between their study and ours was that they found diversity among their six strains for a requirement of antibody for opsonization. All strains were opsonized by fresh normal human serum containing immunoglobulin and complement. Immunoglobulin-deficient serum was opsonic for two of the six strains. They found no strains opsonized by heat-inactivated serum. In our study in which hyperimmune rabbit serum was utilized as a source of antibody, heat-inactivated antiserum was opsonic for five of nine CPA strains, one of $14 \mathrm{MPA}$, and three of 11 NMPA. Our conclusion is that amplification by complement is not always necessary for opsonization when sera which have opsonic titers of $>1: 1000$ are tested and is a consequence of very high levels of anti-Pseudomonas antibody unlikely to be found in human sera.

Our data confirm the studies of Peterson et al. (12) and others which show the diversity of opsonic requirements among classical strains of $P$. aeruginosa. We too have shown a similar variability of activation of the alternative and classical complement pathways among these strains. We can now extend these observations to MPA strains and their non-mucoid derivatives which, al- though showing a similar diversity, also have certain unique properties.

It has been demonstrated previously that certain MPA strains are completely resistant to opsonization (2). This has not been reported to occur with NMPA or CPA strains. Other MPA strains are susceptible to opsonization by complement alone. These strains appear to require an intact classical complement pathway for opsonic activity (as defined by our assay) and within this group there is strain variation as to whether they can be opsonized in the absence of the alternative complement pathway. This is true, too of the NMPA strains derived from MPA strains which show a similar diversity of opsonic requirements and of ability to be opsonized by the two complement pathways.

The diversity of opsonic requirements of $P$. aeruginosa strains from all sources reported here demonstrates the importance of defining these parameters before undertaking studies of pathogenesis. The use of strains with different requirements could have led to conflicting reports from different laboratories. It is conceivable that a strain which could be opsonized by complement alone in our system would behave differently from a strain which 
requires antibody for opsonization in animal or isolated organ models. Such studies have not been performed. A recent study using an animal model suggests MPA and NMPA have the same pathogenic potential but the opsonic requirements of the strains were not reported (5).

The pathogenesis and immunology of MPA is a new research endeavor and less is known about these strains than classical non-mucoid strains. The immunodeterminant for stimulation of protective antibody is unknown. We have shown that for most MPA strains unlike NMPA and CPA strains, antibody to the immunotype antigen is not opsonic. No studies, however, have defined the interaction responsible for opsonization of the rare MPA strains, which can be opsonized by antibody with or without complement. A study by Schwarzmann and Boring (13) suggests the immunodeterminant is the extracellular mucoid material, but the purity of this material was not reported.

The data presented in this report shows that MPA strains can be subdivided into at least two classifications by their ability to bind complement, especially $\mathrm{C} 3$ on the surface. This division corresponds to in vitro resistance to opsonization.

We would define the first classification as strains which bind $\mathrm{C} 3$ according to immunofluorescence with anti-C3. These strains can be opsonized by complement alone. Those of the second classification are strains which do not bind $\mathrm{C} 3$ and are resistant to opsonization by complement alone and the great majority are resistant to opsonization by antibody directed toward the immunotype antigen whether complement is present or not. The relevance of this finding to individuals infected with these strains has not yet been studied. It will be important to look prospectively at patients with $\mathrm{CF}$, who are infected with these strains, from the time of first isolation to see if the strains persist for different lengths of time and if their clinical courses differ. We are in the process of following such patients. Finally, one must be careful in the interpretations of antibody studies of patients infected with MPA strains.

Tests which measure antibody to the immunotype antigen may not reveal information relevant to activity against MPA strains and tests of opsonophagocytosis using fresh patients' sera may demonstrate functional activity which can be accounted for on the basis of complement activity alone.

\section{REFERENCES AND NOTES}

1. Baltimore, R. S., Dobek, A. S., Stark, F. R., and Artenstein, M. S.: Clinical and epidemiological correlates of Pseudomonas typing. J. Infect. Dis., 130 (suppl.): S53 (1974).

2. Baltimore, R. S. and Mitchell, M.: Immunologic investigations of mucoid strains of Pseudomonas aeruginosa: Comparison of susceptibility to opsonic antibody in mucoid and nonmucoid strains. J. Infect. Dis., 141: 238 (1980).

3. Bjornson, A. B. and Michael, J. G.: Contribution of humoral and cellular factors to the resistance to experimental infection by Pseudomonas aeruginosa in mice. I. Interaction between immunoglobulins, heat-labile serum factors and phagocytic cells in the killing of bacteria. Infect. Immun., 4: 462 (1971).

4. Bjornson. A. B. and Michael, J. G.: Factors in human serum promoting phagocytosis of $P$. aeniginosa. I. Interaction of opsonins with the bacterium. J. Infect. Dis., 130 [suppl.]: S119 (1974).

5. Blackwood, L. L. and Pennington, J. E.: Influence of mucoid coating on clearance of $P$. aeruginosa from lungs. Infect. Immun., 32: 443 (1981).

6. Diaz, F., Mosovich, L. L., and Neter, E.: Serogroups of Pseudomonas aeruginos $a$ and the immune response of patients with cystic fibrosis. J. Infect. Dis. 121: 269 (1970).

7. Fisher, M. W., Devlin, H. B., and Gnabasik, F. G.: New immunotype schema for Pseudomonas aeruginosa based on protective antigens. J. Bacteriol., 98 835 (1969).

8. Høiby, N.: Pseudomonas aeruginosa infection in cystic fibrosis. Relationship between mucoid strains of Pseudomonas aeruginosa and the humoral immune response. Acta Pathol. Microbiol. Scand. [B], 82: 551 (1974).

9. Johnston, R. B., Jr., Newman, S. L., and Struth, A. G.: An abnormality of the alternate pathway of complement activation in sickle-cell disease. N. Engl. J. Med., 288: 803 (1973).

10. Kasper, D. L. and Wyle, F. A.: Bactericidal antibody assay using ${ }^{14} \mathrm{C}$-labelled Neisseria meningitidis. Proc. Soc. Exp. Biol. Med., 139: 1175 (1972).

11. Kulczycki, L. L.. Murphy, T. M.. and Bellanti, J. A.: Pseudomonas colonization in cystic fibrosis. A study of 160 patients. J. Am. Med. Assoc.. 240: 30 (1978).

12. Peterson, P. K., Kim, Y., Schmeling, D., Lindemann, M., Verhoef, J., and Quie, P. G.: Complement-mediated phagocytosis of Psetudomonas aentinosa. J. Lab. Clin. Med., 92: 883 (1978).

13. Schwarzmann, S. and Boring, J. R. III: Antiphagocytic effect of slime from a mucoid strain of Pseudomonas aeruginosa. Infect. Immun.. 3: 762 (1971).

14. Wood, R. E., Boat, T. F., and Doershuk, C. F.: Cystic fibrosis. Am. Rev. Respir. Dis., 113: 833 (1976).

15. Young, L. S. and Armstrong, D.: Human immunity to Pseudomonas aeruginosa. I. In vitro interaction of bacteria. polymorphonuclear leukocytes, and serum factors. J. Infect. Dis., I26: 257 (1972).

16. Young, L. S.: Role of antibody in infections due to Pseudomonas aeruginosa. J. Infect. Dis.. 130 [Suppl.]: S 111 (1974).

17. Presented in part at the Twenty-first Interscience Conference on Antimicrobial Agents and Chemotherapy, Chicago, Illinois, November 5, 1981.

18. Requests for reprints should be addressed to: Dr. Robert S. Baltimore, Department of Pediatrics, Yale University School of Medicine, 333 Cedar Street. New Haven, CT 06510.

19. This research was supported in part by a grant from the Cystic Fibrosis Foundation and Grant AI1728I, from the National Institute of Allergy and Infectious Diseases. We appreciate the advice of Drs. George Miller and Eugene Shapiro and the excellent manuscript preparation of Joyce Nepiarsky. 20. Received for publication August 26, 1982.

21. Accepted for publication April 13, 1983. 